\title{
Human memory research: Current hypotheses and new perspectives
}

Antônio Jaeger. Universidade Federal de Minas Gerais. Cesar Alexis Galera. Universidade de São Paulo (Ribeirão Preto).

Lilian Milnitsky Stein. Pontifícia Universidade Católica do Rio Grande do Sul.

Ederaldo José Lopes. Universidade Federal de Uberlândia.

\begin{abstract}
Research on human memory has increased significantly in the last few decades. Inconsistencies and controversies inherent to such research, however, are rarely articulated on published reports. The goal of the present article is to present and discuss a series of open questions related to major topics on human memory research that can be addressed by future research. The topics covered here are visual working memory, recognition memory, emotion and memory interaction, and methodological issues of false memories studies. Overall, the present work reveals a series of open questions and alternative analysis which could be useful for the process of hypothesis generation, and consequently for the design and implementation of future research on human memory.
\end{abstract}

Keywords: memory; human memory; hypotheses.

\section{Resumo}

Pesquisa em memória humana: Hipóteses atuais e novas perspectivas. A pesquisa em memória humana aumentou significativamente nas últimas décadas. Inconsistências e controvérsias inerentes a pesquisas com este foco, entretanto, são raramente articuladas nas publicações especializadas. O objetivo do presente artigo é apresentar e discutir uma série de questões abertas relacionadas aos principais tópicos de pesquisa em memória humana, e que podem vir a ser abordados por pesquisas futuras. Os tópicos abordados no presente estudo são memória operacional visual, memória de reconhecimento, interação entre emoção e memórias e aspectos metodológicos do estudo de falsas memórias. De forma geral, o presente trabalho revela uma série de questões em aberto e análises alternativas que podem ser úteis para o processo de geração de hipóteses, e consequentemente para o desenvolvimento de pesquisas futuras sobre a memória humana.

Palavras-chave: memória; memória humana; hipóteses.

\section{Resumen}

Investigación en la memoria humana: Hipótesis actuales y nuevas perspectivas. La investigación en la memoria humana ha aumentado significativamente en las últimas décadas. Las inconsistencias y controversias inherentes a la investigación con este enfoque, sin embargo, rara vez se articulan en publicaciones especializadas. El objetivo de este trabajo es presentar y discutir una serie de cuestiones abiertas relacionadas con los temas principales de la investigación en la memoria humana, y que pueden ser abordados por investigaciones futuras. Los temas tratados en este estudio son la memoria de trabajo visual, la memoria de reconocimiento, la interacción entre la emoción y las memorias y los aspectos metodológicos del estudio de las falsas memorias. En general, este estudio revela una serie de cuestiones abiertas y alternativas de análisis que pueden ser útiles para el proceso de generación de hipótesis, y en consecuencia para el desarrollo de futuras investigaciones sobre la memoria humana.

Palabras clave: memoria; memoria humana; hipótesis. 
Research on human memory has greatly proliferated in the last few decades. Such intense proliferation, however, may paradoxically overshadow some unanswered questions in the field of memory research. While this increase in volume of research may supply interested readers with an abundance of data and results, it may not necessarily be helpful in terms of revealing for him or her the main controversies and inconsistencies in the field. Thus, our goal in this paper is to discuss some hypotheses that we consider central to the advance of the study of human memory from a cognitive psychology perspective. Instead of focusing on new data, we pursued to reveal a set of controversies and open questions in the field of human memory research. Such controversies and open questions, we believe, may be useful as bases for generating hypothesis for future research (McGuire, 1997).

The first controversy we approach concerns current theories of visual working memory. We discuss unexpected effects in visual working memory tasks apparently generated by task-irrelevant visual information (Logie, 1995; 2011). That is, task-irrelevant visual information causes deleterious effects on working memory capacities for information that cannot be semantically encoded. Stimuli that can be semantically encoded, on the other hand, tend to be more resistant to such visual interference. This finding, nonetheless, is not consistently replicated, and characteristics of task and stimulus may underlie such inconsistency. Thus, we suggest that an important approach for future research is to identify stimuli dimensions that can be determinant to make such short-term visual representations either resistant or susceptible to irrelevant visual inputs.

Another topic concerns the debate about singleversus dual-process theories of recognition memory (Wixted, 2007; Yonelinas, 2002). To study recognition memory, researchers usually let participants encode a set of items (i.e., targets), and later discriminate them from novel items (i.e., distracters). According to single-process theories, such discrimination process is based primarily on a strength-like signal of familiarity, whereas according to dual-process theories, such discrimination is typically based on a combination of familiarity signal with additional contextual and detailed episodic information. These conflicting approaches provide different predictions regarding behavioral performance, and we discuss the potential corroboration (or refutation) of such predictions by experimental findings.
We discuss several unresolved issues concerning the interaction between emotion and memory in the section Emotion and Memory Accuracy of the present article. We discuss first the parallel increase in memory accuracy for central and decrease for peripheral details of emotional events (Pickel, 2007); a phenomenon often termed "weapon focus effect". Although several studies have shown that emotional information is more memorable than neutral information (Hamann, 2001), the former also appears to be more susceptible to distortion. Another important topic discussed in the referred section, is the methodological limitations of extant studies investigating the interaction between memory and emotion. Such methodological limitations should be carefully approached by future research. In this section, we also approach predictions concerning the influence of emotion on false memories based on the Fuzzy-Trace Theory, emphasizing its theoretical relevance for further research.

Finally, we consider current data analysis approaches to false memory, and suggest that systematic analysis of reaction times could be a successful approach for future research. Reaction times data has been rarely implemented on false memory studies, such as the DRM paradigm (Roediger \& McDermott, 1995). Balota and Yap (2011) have already shown that reaction time analysis could have the potential of bringing relevant advances for the field.

In sum, we approach several topics on memory research in the following sections. In contrast to a typical review article, however, these topics are discussed in terms of their unanswered questions, inconsistencies, and controversial issues. We expect that the discussion of such issues motivate the generation of new hypothesis for future research, and consequently help to advance the comprehension of human memory.

\section{Working Memory and Irrelevant Visual Input}

The visual working memory construct (VWM), as proposed by Logie (1995), contains two structures, the visual cache and the inner scribe. The visual cache, or visual short-term store, stores visual representations, as color and shape of stimuli. The inner scribe, on the other hand, stores spatial information and is responsible for the rehearsal of the visuo-spatial content stored in the visual cache. The VWM is analogous to the phonological memory construct proposed by Baddeley and Hitch (1974; see also Baddeley, 1986) containing two subsystems, a passive store directly accessed by sensory phonological 
information (Salamé \& Baddeley, 1982), and a rehearsal process that maintains information active in the passive store. Unlike the phonological memory model, however, visual sensory information cannot reach the visual cache directly (Logie, 2011). Representations stored in the visual cache are acquired through vision, tactile or verbal descriptions of environmental scenes, and interpreted according to long-term based knowledge. These representations contain, in abstract form, the necessary information to reconstruct visual mental images that can be inspected and manipulated consciously.

The proposal that visual information reaches the visual cache indirectly has been put into question in theoretical grounds (Baddeley, 2007; Pearson, 2001; Quinn, 2008, 2012) and in experimental studies using irrelevant visual input techniques. One such technique, the Dynamic Visual Noise (DVN), consists in a flickering black and white dot pattern similar to that produced by a TV screen out of tune. It impairs performance in memory tasks wherein mental images are created from verbal instructions (pegword). The DVN impairs performance on these tasks when administered during both encoding and retrieval (Andrade, Kemps, Werniers, May, \& Szmalec, 2002; McConnell \& Quinn, 2000, 2004; Quinn \& McConnell, 1996, 2006), but not during retention intervals (Quinn \& McConnell, 2006). The DVN also impairs memory performance when stimuli are presented visually, although the effect of noise is less consistent in this case. For example, the DVN has no significant effects on recognition of Chinese characters (Andrade et al., 2002) or on recognition of randomly filled matrices (Avons \& Sestieri, 2005), although it may affect the confidence of participants on the accuracy of their recognition judgments (Kemps \& Andrade, 2012). In other studies, the DVN affected performance in recognition tasks for the exact size of circles (McConnell \& Quinn, 2003), color shades (Dent, 2010; Pereira \& Galera, n.d.), texture (Dean, Dewhurst, \& Whittaker, 2008) and graphical fonts (Darling, Della Sala, \& Logie, 2009; Santana, Godoy, Farias, Ferreira, \& Galera, 2013).

The simplest account for differences of DVN effects on memory and visual image tasks is methodological. In visual image tasks, presentation of DVN and generation of mental images are simultaneous. Assuming that perception and generation of mental images activate overlapping brain regions, as proposed by Kosslyn (1994), the impairment caused by the presentation of DVN can result from the interference of irrelevant perceptual information during the generation of mental images. In visual memory tasks, the DVN is presented after stimuli have been moved from perception to a more stable representation, possibly in the shortterm visual memory. Thus, irrelevant information affects the conscious generation of visual images, but not the storage of visual representations in the short-term visual store, whether arising from perception or long-term memory (Borst, Niven \& Logie., 2012; Logie, 2011; Quinn, 2008, 2012).

Methodological differences in visual image and visual memory tasks may explain the difference between effects of DVN in these two types of task. However, it does not explain why DVN impairs recognition of some types of stimuli, while leaving others unaffected. Differences between effects of DVN on memory tasks with more complex stimuli, such as Chinese characters or geometric patterns (Andrade et al., 2002; Avons \& Sestieri, 2005), and tasks that rely on recall of size, color or shape details (Darling et al., 2009; Dent, 2010; McConnell \& Quinn, 2004; Pereira \& Galera, n.d.; Santana et al., 2013) have yet to be explained. Quinn (2012) suggests that different systems may be involved in the storage of these two broad types of stimuli. Complex stimuli, such as Chinese characters and visual patterns, are easier to encode semantically, whereas stimuli involving subtle variations in size, color, and shape, remain for longer in a pre-semantic visual store, which is more susceptible to interference from sensory or perceptual information. Orme (2009), who showed that more easily nameable visual patterns are less sensitive to the effect of the DVN, obtained evidence that corroborates this assumption. Darling, et al. (2009) showed that the DVN impairs the recognition of graphical fonts, and suggested that in visual memory tasks the maintenance of complex stimuli requires continuous generation of representations, exposing these representations to deleterious effects of irrelevant visual inputs. Such issues could be investigated by future research by assessing the amount of details required to impair the maintenance of graphical fonts and Chinese characters (Andrade et al., 2002) and randomly filled matrices on working memory (Avons \& Sestieri, 2005).

In sum, even though some studies attribute the variable effects of DVN to rehearsal or to generation processes involved in the maintenance of memorized representations on consciousness (Darling et al., 2009; McConnell \& Quinn, 2003), such different effects for different stimuli remains an open question. Thus, the identification of stimuli dimensions that determine whether visual representations are affected by irrelevant 
visual input is an important goal for future research. Findings from such studies could extend our knowledge regarding visual short-term memory, as well as regarding the connection of such process to the visual buffer. In addition, further studies considering consolidation processes (Vogel, Woodman, \& Luck, 2006) can also be beneficial to expand the current knowledge about the contribution of early visual processing to visual shortterm memory (e.g., van de Ven, Jacobs, \& Sack, 2012).

\section{Recognition Memory: Single Versus Dual-process Models}

In typical recognition memory tasks, individuals are asked to discriminate previously encoded items from novel items. Such tasks usually contain an encoding phase wherein lists of items are presented to volunteers, and a test phase wherein items presented at the encoding phase are presented again, intermixed with novel items. During the test phase, participants judge whether each item has been previously encountered at the encoding phase or not. There are currently two divergent theoretical views regarding the cognitive processes engaged during recognition memory tasks. According to the 'single process' view, recognition memory depends exclusively on a strength-like memory signal, usually referred to as familiarity (Benjamin, Diaz, \& Wee, 2009; Verde \& Rotello, 2007). According to the 'dual process' view, on the other hand, recognition memory involves a combination of familiarity processes and retrieval of contextual or qualitative details linked to each item, a process termed 'recollection' (Mandler, 1980; Yonelinas, 2002). In this section, we discuss arguments in favor and against each of these models, while highlighting some topics that can be further explored by future research.
Single process models have been traditionally based on the Signal Detection Theory (SDT; Macmillan \& Creelman, 2004). Initially proposed as a framework to account for psychophysics findings (Green \& Swets, 1966), SDT became extensively employed to accommodate findings from recognition memory experiments. As can be seen in Figure 1A, according to the original signal detection framework, memory strength can be represented by a continuous horizontal axis in which information more to the left of the axis have a less intense memory signal (i.e., weak memories), whereas information to the right a more intense memory signal (i.e., strong memories). Thus, in recognition memory tests, 'old' and 'new' items can be described by two Gaussian distributions (Figure $1 \mathrm{~A}$ ), with the distribution to the left representing new items and the one to the right old items. In order to perform recognition judgments, individuals establish an arbitrary cutoff point (criterion), and items falling to the left of this point are classified as 'new' while items falling to the right are classified as 'old' (Macmillan \& Creelman, 2004).

Since its initial proposal as a framework to account for recognition memory, SDT was adopted by several memory theorists as the framework of choice for characterizing this phenomenon (e.g., Morrell, Gaitan, \& Wixted, 2002; Turner, Van Zandt, \& Brown, 2011). The main reason for this is perhaps the elegance and parsimony of the model, its consistency with a number of theories of memory (e.g., Global Matching Models; Clark, \& Gronlund, 1996), and its outstanding capacity of generating useful indexes to measure memory performance (e.g., $d$ ' to measure accuracy and $C$ to response bias, Snodgrass \& Corwin, 1988). The question remains, however, of whether this model can be
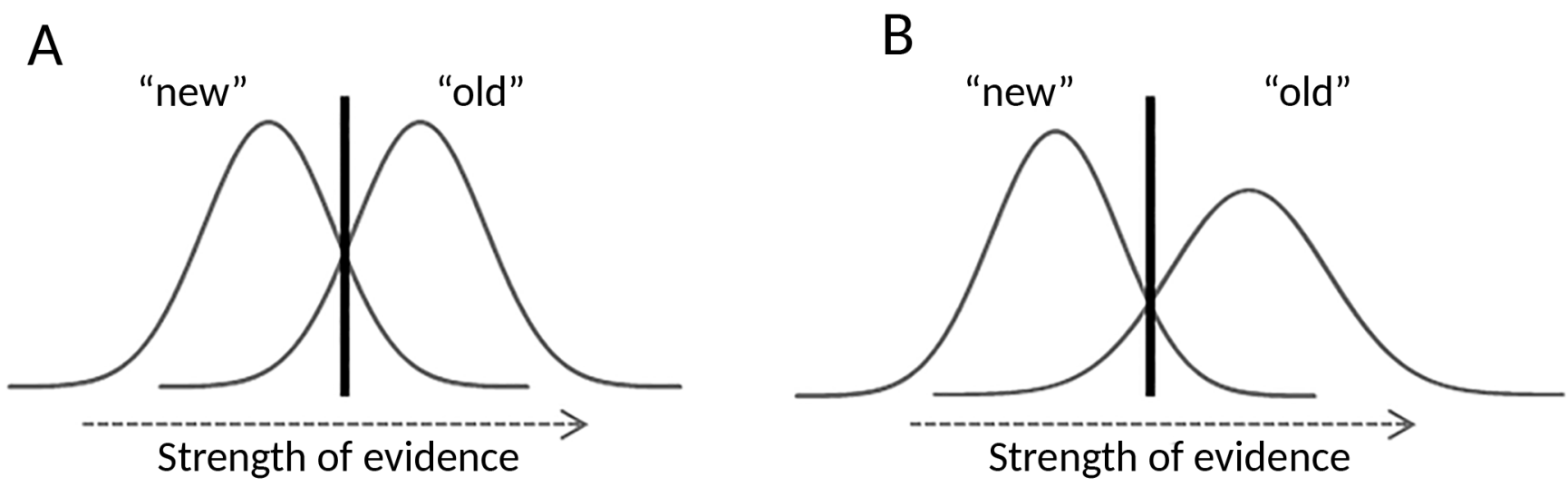

Figure 1. Basic equal variance signal detection model (A), and unequal variance signal detection model (B). On panels $A$ and $B$, horizontal arrows represent strength of memory evidence. The curves represent the distribution of memory signal from new and old items, and the vertical lines represent criterion. 
regarded as a true theoretical description of the process of recognition memory instead of just a pragmatic framework to measure memory performance. Note that if one assumes that this model is a true description of recognition memory, one must assume also that recognition memory is based solely on familiarity processes. Therefore, the chief question here is whether the process of familiarity is enough to account for the phenomenon of recognition memory or not.

Even though findings from recognition memory experiments are roughly consistent with the traditional SDT framework, subtle inconsistencies advanced by later memory researchers exposed a number of limitations inherent to single process models of recognition (Yonelinas, 1994). That is, unpredicted asymmetries encountered in analyses of receiveroperating characteristics (ROC, Macmillian \& Creelman, 2004) indicate that whereas encoded items are frequently recognized with high levels of confidence, such highly confident judgments are unexpectedly rare to novel items mistakenly classified as 'old' (i.e., false alarms, see Figure 2). Such pattern suggests that high confidence responses to encoded items are often accompanied by explicit retrieval of vivid contextual details, indicating the presence of recollective processes during their recognition. Further research showed that the asymmetries brought to attention by Yonelinas are remarkably consistent (for a review, see Yonelinas \& Parks, 2007), suggesting that recollection plays an important role during recognition of encoded items (see Figure 2).

These findings have instigated a heated debate between proponents of single and dual-process models of recognition memory, a debate that does not seem to become resolved anytime in the near future. Researchers favorable to single process models have proposed adjustments to the original models in order to account for the ROCs asymmetries highlighted by Yonelinas (1994). Perhaps the most accepted updated single process model is the unequal variance signal detection model proposed by Mickes, Wixted and Wais (2007). According to this model, the distributions of novel and
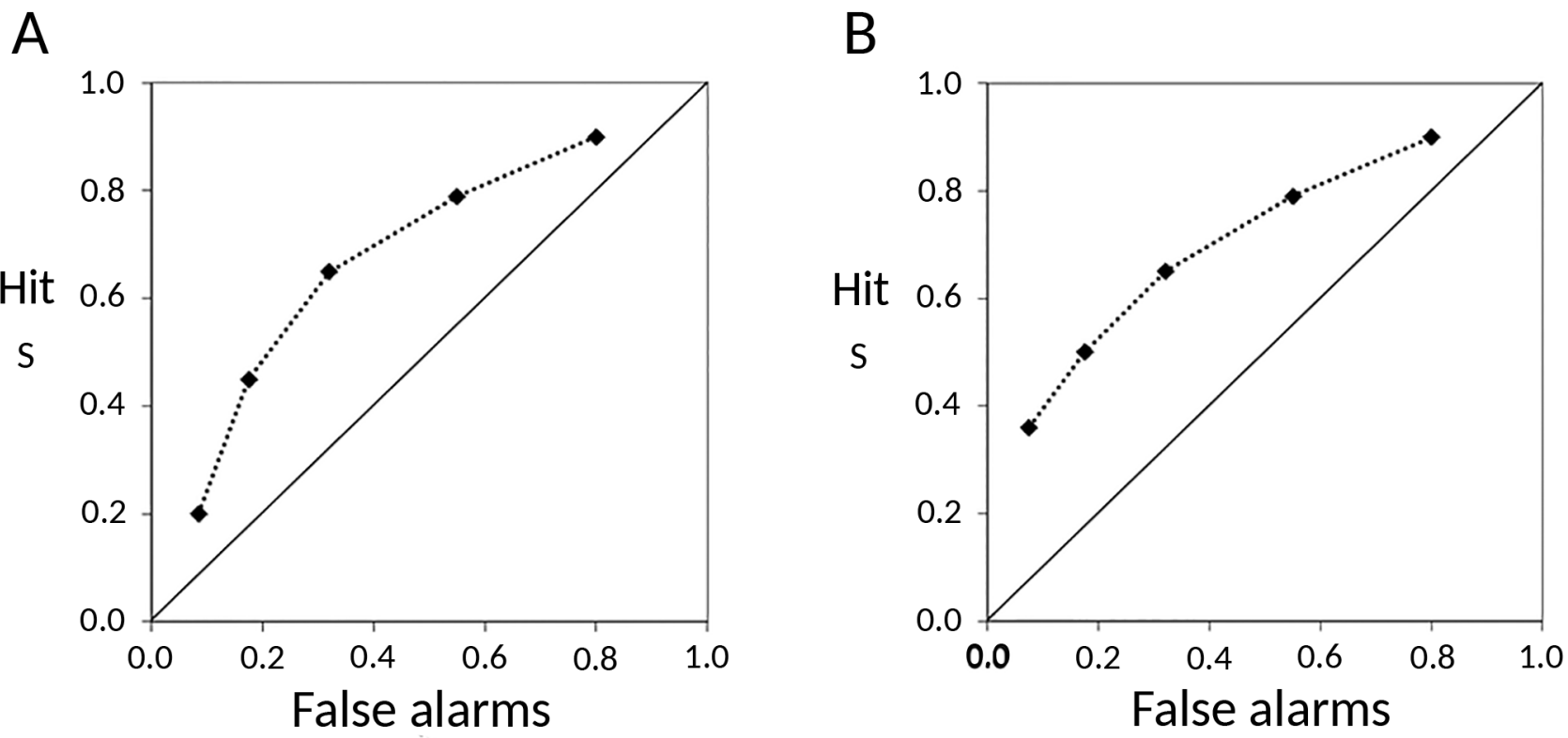

Figure 2. Illustrative ROCs predicted by equal variance signal detection models (A) and by dual process models (B). ROCs can be derived from recognition memory experiments in which participants rate their confidence on each of their responses (i.e., Likert scales from high confident "old" to high confident "new"). Thus, in panels A and B, the bottom left point in the graph represents the proportion of high confidence "old" responses for both actual old items (hits - $y$-axis) and for new items (false alarms - x-axis). The following point (second from left to right), represents the proportion of medium confidence "old" responses for both old items (hits) and new items (false alarms). The third, forth, and fifth points from left to right represent the proportions of low confidence "old", low confidence "new" and medium confidence "new" responses for actual old and new items respectively. It is important to note that these proportions are cumulative, thus the second point from left to right, for example, is the proportion of medium confidence "old" responses plus the proportion of high confidence "old" responses; the third point is the proportion of low confidence "old" plus the proportions of medium and high confidence "old" responses, and so on. Notably, the proportion of high confidence "old" responses for actual old items (hits) is higher in panel B than in panel A, while the proportion of high confidence "old" responses to new items (false alarms) are equivalent in both panels. Such increased proportion of high confidence for hits generates an asymmetry in the ROC curve (panel $\mathrm{B})$, and is interpreted by dual process theorists as resulting from recollective processes restricted to high confidence old responses. 
encoded items have different variances at test (see Figure 1B). That is, this model proposes that in typical recognition tests, the distribution of novel items is about $20 \%$ less variable than the distribution of encoded items. Even though this modified version of the original signal detection model is capable of account statistically for the aforementioned ROC asymmetries, it is not clear what this difference in variance means psychologically. One could suggest that 'old' items are encoded with variable strength, becoming items with variable memory strength at test (Jang, Mickes, Wixted, 2012; Wixted, 2007).

It is not clear, nonetheless, why novel items should not exhibit the same pattern. Note that as well as encoded items, novel items in typical recognition memory tests are common pieces of information (i.e., words, figures) usually well known to research participants (e.g., relatively frequently read/spoken words encoded at a prior point of each participant's lifetime). So, were not novel items supposed to be variable as well? Furthermore, in typical recognition tests old items were all encountered recently in an encoding list, while new items were encountered for the last time in different moments and contexts in each participant's natural environment. Then, would it not be more reasonable to expect the opposite of the pattern proposed by Wixted (2007)? That is, novel items imbued with a more variable memory signal than old items. This issue is in need of further research, which could be determinant to reveal the process or processes engaged during recognition memory.

The question under debate is simple. How many cognitive processes people engage during recognition memory? Despite its simplicity, future studies should approach this question properly. An undesired but often widespread practice in psychological research is the reification of poorly defined mental constructs. In cognitive neuroscience studies, for instance, a variety of memory tasks are assumed to engage recollection (Rugg \& Yonelinas, 2003), and although such process is likely to be engaged by a significant part of such tasks, a stronger agreement about the involvement of this process in recognition should be reached. Otherwise, researchers risk assigning brain activations to mental constructs that have theoretical weaknesses in their most basic assumptions.

Novel experimental paradigms pursuing to dissociate processes of familiarity and recollection during recognition tasks may be a useful approach to investigate this issue. The remember-know paradigm, for example, have been used for several years to investigate these processes (Tulving, 1985). In experiments using such paradigm, participants report whether they recollect qualitative information associated with each item ("remember"), or just know they encountered the item in the encoding list, without recollecting any contextual information ("know"). In an interesting version of this paradigm (Gardiner, Ramponi, \& Richardson-Klavehn, 1998), participants were asked to provide verbal explanations for a subset of their remember/know responses. The results suggest that only explanations following "remember" responses included descriptions of recollective experiences, while explanations following "know" responses included mostly feelings of familiarity. Updated versions of this paradigm can be extremely profitable to increase the current knowledge regarding phenomenological aspects of experiences of recollection and familiarity (see Selmeczy \& Dobbins, 2014).

\section{Emotion and Memory Accuracy}

There is a long history of investigation on how emotion influences memory. Reisberg and Heuer (2007) provide a comprehensive review of this issue, which reveals inconclusive results. That is, emotional stimuli tend to increase the retention of both central details and the gist of events. Such facilitation, however, does not necessarily result in accurate memories. The phenomenon of flashbulb memory illustrates this issue. Talarico and Rubin (2003) reported that the recall of details of the terrorist attacks on September 11, a highly emotional event, was as accurate as the recall of everyday events, with participants showing significant forgetting over time. Interestingly, nonetheless, they also showed that ratings of recollection and vividness declined solely for everyday memories, while remaining constant for the September 11 episode (see also Phelps \& Sharot, 2008).

In contrast to its effects on central details of events, emotional factors can decrease memory accuracy for peripheral details of episodes, as in the weapon focus effect (e.g., Pickel, 2007). To further complicate matters, the level of emotion expressed and/or the degree of stress experienced during an event must also be taken into account, as even details that are central to the event may be subject to distortion under extreme emotional conditions as opposed to neutral circumstances (Deffenbacher, Bornstein, Pewnrod, \& McGorty, 2004).

Another factor to be considered in the investigation of the influence of emotion on memory, is emotional valence (i.e., positive and negative emotions). 
The question at issue here is how the retention of memories for emotional events compares to the retention of memories for neutral events. Many lines of investigation have shown that emotional events are more memorable than neutral events (Hamann, 2001; Kensinger, 2004; LaBar \& Cabeza, 2006). Nonetheless, some studies have demonstrated that emotional memories are also more susceptible to distortion. For instance, autobiographical memory studies have indicated that memories for emotional events are heavily vulnerable to distortion (Levine, 1997; Schmolk, Buffalo, \& Squire, 2000; Talarico \& Rubin, 2003). Although these ecologically relevant studies provide precious insights about how people remember events in the real world, they have some methodological disadvantages in comparison to laboratories investigations. In autobiographical studies, for example, the exactly conditions in which target events were encoded are unknown, and thus the accuracy of the autobiographical event cannot be properly checked (Berntsen, 2002; Reisberg \& Heuer, 2004).

The issue of whether or not memories for emotional valenced items are susceptible to distortion was also investigated by laboratory studies. Some of these studies have used the Deese- Roediger-McDermott paradigm (DRM; Roediger \& McDermott, 1995), which was adapted to the Brazilian population (Stein \& Perguer, 2001; Stein, Feix, \& Rohenkohl, 2006), and was design to examine whether emotional critical lures could be falsely remembered (Budson et al., 2006; Kensinger \& Corkin, 2004a; Pesta, Murphy, \& Sanders, 2001). The DRM paradigm involves the presentation of lists of words (e.g., table, sit, legs, seat...), each of which is highly associated with a single, non-presented word (e.g., chair), referred to as the critical lure. After participants read or hear such lists, they typically show a high tendency to falsely recall or recognize the critical lures. These researchers have shown that while emotional lures are falsely remembered, they have also reached the conclusion that memory for emotional information are less likely to be distorted than neutral information. Nevertheless, these studies present some methodological limitations that prevent one from making more conclusive assumptions regarding the effect of emotion on memory distortion.

In the experiments reported by Pesta et al. (2001) and Kensinger and Corkin (2004a), after studying lists of non-emotional words orthographically associated with a nonpresented neutral lure (e.g., link, mink, and sink were related with rink) or an emotional lure (e.g. cape, nape, tape, related to rape), individuals were less likely to falsely recall or to falsely recognize emotional lures than neutral lures. A limitation of these studies, however, is that the majority of studied words were neutral. Therefore, a decrease in false alarms to emotional lures was perhaps an effect of semantic incongruence with targets, a form of distinctiveness, rather than a specific effect of emotion on memory (Kensinger \& Schacter, 2006; Schacter, Gallo, \& Kensinger, 2007). Budson et al. (2006), in a departure from the two previous studies, used lists containing both neutral and emotional words that were semantically associated in the study phase. Their findings indicated no effect of emotion on false memory reports. Nevertheless, these findings might be taken with caution, since there was no control for semantic relatedness between studies lists and lures.

Overall, several studies addressing memory distortion for emotional information have limitations: (a) materials are mostly non-emotional; (b) semantic relatedness of study and test materials are not controlled;(c) materials are not standardized for emotional dimensions (valence and arousal); (d) positive and negative valenced materials are not compared.

Regarding the theoretical accounts for distortions of memories of emotional information, we hypothesize that two independent memory traces are responsible for true and false recognition in the DRM paradigm (see also Budson et al., 2006). This hypothesis is based on the Fuzzy Trace Theory (Brainerd \& Reyna, 2005), which proposes that gist traces store the meaning of the experience, whereas verbatim traces store specific features of the experience. False memories result from remembering gist traces while not remembering verbatim representations. Veridical memories, on the other hand, result from remembering both item-specific verbatim and gist traces. Therefore, assuming that emotion enhances memory for specific features of the study list (i.e., verbatim trace), one would predict that false recognition of both negative and positive emotional lures would decrease relative to emotionally neutral lures. Conversely, assuming that emotion enhances only the gist trace of the study list, one would predict that the false recognition of emotional lures could actually be greater than that of non-emotional lures. That is, levels of false recognition for emotional lures would increase or decrease depending upon the specific memory trace enhanced by emotion. Such prediction remains in need of further experiments, which could circumvent the limitations of the studies mentioned above. 


\section{False Memories in Short-Term Tasks: Contributions of Reaction Time Measures}

Among the distortions encountered in human memory, the phenomenon of false memories (FM) has been taking a prominent position due to its importance in daily events, as well as in experimental studies (for a review, see Stein \& Cols., 2010). FMs can be conceptualized either as memories for events that have never occurred, or memories that differ significantly from their original events (Alves \& Lopes, 2007; Brainerd \& Reyna, 2005; Mazzoni \& Scoboria, 2007; Stein et al., 2010). The experimental procedure used in most current FM research is the abovementioned DRM paradigm (Gallo, 2010; Pezdek \& Lam, 2007; Roediger \& McDermott, 1995). Although the FM effects elicited by this paradigm are considerably robust, the majority of studies employing such paradigm use tasks of recall and recognition, having as dependent variable the proportion of distortions on these indices. Moreover, research using the DRM has focused on long-term episodic memory for verbal material, a type of memory that can be significantly distorted after intervals of weeks or months (Atkins \& Reuter-Lorenz, 2008).

An open question regarding FMs is whether such phenomenon is circumscribed to long-term memory. There is substantial evidence suggesting that semantic coding can also be found in short-term memory tasks (Bartha, Martin, \& Jensen, 1998; Flegal, Atkins, \& Reuter-Lorenz, 2010; Haarmann \& Usher, 2001; Jones \& Anderson, 1982; Shulman, 1972), a proposal also supported by neuropsychological studies (R. C. Martin \& Romani, 1994; N. Martin \& Saffran, 1992). Such evidence make the possibility of studying FM in short-term tasks promising, and allow for the use of reaction time (RT) as a dependent variable in combination with the commonly used accuracy measures (Galera \& Lopes, 1995; Lopes \& Garcia, 2014). The greatest advantage of such approach is that it can provide finer-grained knowledge about basic memory processes in comparison to accuracy measures alone (Balota \& Yap, 2011; Luce, 1986; Welford, 1980).

The use of RT measures to study cognition grew steadily since the S. Sternberg's (1966) seminal paper, which was among the most cited papers in the 60's, 70's and early 80 (White, 1983). A search in PsychINFO with the keywords memory scanning, memory search and Sternberg's task, crossed with the keywords false memories or false memory, in the period from 1950 to 2010, revealed that only the study of Coane, McBride,
Raulerson and Jordan (2007) used the task proposed by S. Sternberg to study false memories on DRM lists. Those authors manipulated stimuli set size (three, five and seven words) and test type (targets, critical distracters, and unrelated distracters), having RT and proportion of errors as dependent variables. This study showed that critical distracters were both more falsely recognized than unrelated distracters, and slower to be correctly rejected than unrelated distracters. As expected, RTs also increased as a function of number of memorized stimuli.

Similar findings were reported by Atkins and Reuter-Lorenz (2008). These authors showed an increase in RTs for critical distracters using an interval of 4 seconds between study and test. These results were further replicated in an experiment wherein task-related neuroimaging data were collected to examine the role of prefrontal cortex regions (PFC) during false recognition versus correct rejection of critical distracters (Atkins \& Reuter-Lorenz, 2011). Since it has been extensively demonstrated that $\mathrm{PFC}$ regions, such as left ventrolateral PFC and dorsolateral PFC, are involved in cognitive control during resolution of semantic interference (e.g., Badre \& Wagner, 2007), decreases in the activity of these regions during false recognition may suggest that false memories are a consequence of reduced cognitive control. The neuroimaging data reported by Atkins and Reuter-Lorenz showed that these predictions were supported for the left dorsolateral PFC (i.e., there was a decrease in the activity of this region during false recognition). These authors interpreted this finding as evidence for the proposal that when items produce high levels of interference, as in the case of the DRM critical distracters, cognitive control processes supported by the left dorsolateral PFC are responsible for the maintenance of accuracy (i.e., they prevent false recognition).

Sene, Lopes and Rossini (2014), using the Brazilian version of the DRM lists (Stein \& Perguer \& 2001; Stein et. al, 2006), showed that RTs were significantly increased as a function of test type due to an increase in memory load, and this increase was higher for critical distracters (FMs) with a memorized set of seven words. Similarly, the percentage of errors significantly increased due to increase in memory load and this increase was higher in the critical distracter condition with the memorized set of seven words. From the memorized set of size three to size seven, percentage of false alarms to critical distracters increased eight times! (Sene et al., 2014).

Current reaction time findings regarding false memories in short-term tasks is a promising ground 
for future investigations. Such investigations can focus on analysis of RT distributions for different types of tests, focus on the study of processing types (serial $\mathrm{x}$ parallel, e.g., Galera \& Lopes, 1997; Townsend, 1990), manipulations of retention interval and memory load in the Sternberg's task, or interfering tasks in working memory paradigms. Results from such experiments, combined with existing theories of long-term memory, short-term memory and working memory can shed new light on the rich and interesting phenomenon of false memories.

\section{Concluding remarks}

Currently, a major challenge faced by students and researchers is to identify what is really important or relevant among the ever increasing amount of publications on a given research field. This can be especially difficult when instead of novel and potentially promising results, the student or researcher is interested in the limitations and inconsistencies inherent to a given research field. Unfortunately, difficulties like this are also common for those who are interested in human memory. Our goal here was to expose such inconsistencies, and to summarize unanswered questions that can be especially relevant for the process of hypothesis generation on human memory research (McGuire, 1997). Thus, in the present article we exposed and discussed several issues concerning the study of human memory that can potentially become raw material for the development of future research. The article focused on issues inherent to the study of working memory processes, long-term memory recognition, emotion and memory interaction, and analysis of false memory data. All approached topics revealed puzzling inconsistencies and open questions, suggesting that theorizing on human memory would profit greatly from further and improved studies on these topics.

\section{References}

Alves, C. M.; \& Lopes, E. J. (2007). Falsas memórias: questões teóricometodológicas. Paidéia (Ribeirão Preto), 17, 45-56. doi: 10.1590/ S0103-863X2007000100005

Andrade, J., Kemps, E., Werniers, Y., May, J., \& Szmalec, A. (2002). Insensitivity of visual short-term memory to irrelevant visual information. The Quarterly Journal of Experimental Psychology, 55(3), 753-774. doi: 10.1080/02724980143000541

Atkins, A. S., \& Reuter-Lorenz, P. A. (2008). False working memory? Semantic distortion in a mere 4 seconds. Memory \& Cognition, 36 , 74-81. doi: 10.3758/MC.36.1.74
Atkins, A. S., \& Reuter-Lorenz, P. A. (2011). Neural mechanisms of semantic interference and false recognition in short-term memory. Neurolmage, 56, 1726-1734. doi:10.1016/j.neuroimage.2011.02.048

Avons, S. E., \& Sestieri, C. (2005). Dynamic visual noise: No interference with visual short-term memory or the construction of visual images. European Journal of Cognitive Psychology, 17(3), 405-424. doi: 10.1080/09541440440000104

Baddeley, A. D. (1986). Working memory. London: Oxford University Press.

Baddeley, A. D. (2007). Working memory, thought, and action. New York: Oxford University Press.

Baddeley, A. D., \& Hitch, G. J. (1974). Working memory. In G. H. Bower (Ed.), The Psychology of learning and motivation (Vol. 8, pp. 47-89). New York: Academic Press. doi: 10.1016/S0079-7421(08)60452-1

Badre, D., \& Wagner, A. D. (2007). Left ventrolateral prefrontal cortex and the cognitive control of memory. Neuropsychologia, 45, 2883-2901. doi: 10.1016/j.neuropsychologia.2007.06.015

Balota, D. A., \& Yap, M. J. (2011). Moving beyond the mean in studies of mental chronometry: the power of response time distributional analyses. Current Directions in Psychological Science, 20(3), 160166. doi:10.1177/0963721411408885

Bartha, M. C., Martin, R. C., \& Jensen, C. R. (1998). Multiple interference effects in short-term recognition memory. American Journal of Psychology, 111, 89-118. doi: 10.2307/1423539

Benjamin, A. S., Diaz, M., \& Wee, S. (2009). Signal detection with criterion noise: Applications to recognition memory. Psychological Review, 116, 84-115. doi: 10.1037/a0014351

Berntsen, D., \& Rubin, D. C. (2002). Emotionally charged autobiographical memories across the life span: the recall of happy, sad, traumatic and involuntary memories. Psychology and Aging, 17(4), 636-652. doi: 10.1037/0882-7974.17.4.636

Borst, G., Niven, E., \& Logie, R. H. (2012). Visual mental image generation does not overlap with visual short-term memory: A dualtask interference study. Memory and Cognition, 40(3), 360-372. doi: 10.3758/s13421-011-0151-7

Brainerd, C. J., \& Reyna, V. F. (2005). The science of false memory. New York: Oxford University Press.

Budson, A. E., Todman, R. W., Schacter, D. L. (2006). Gist memory in Alzheimer's disease: evidence from categorized pictures. Neuropsychology, 20, 113-122. doi:10.1037/0894-4105.20.1.113.

Clark, S. E., \& Gronlund, S. D. (1996). Global matching models of recognition memory: How the models match the data. Psychonomic Bulletin \& Review, 3, 37-60. doi: 10.3758/BF03210740

Coane, J. H.; McBride, D. M.; Raulerson, B., III; \& Jordan, J. S. (2007). False memory in a short-term memory task. Experimental Psychology, 54, 62-70. doi: 10.1027/1618-3169.54.1.62

Darling, S., Della Sala, S., \& Logie, R. H. (2009). Dissociation between appearance and location within visuo-spatial working memory. The Quarterly Journal of Experimental Psychology, 62(3), 417-425. doi: 10.1080/17470210802321984

Dean, G. M., Dewhurst, S. A., \& Whittaker, A. (2008). Dynamic visual noise interferes with storage in visual working memory. Experimental Psychology, 55(4), 283-289. doi: 10.1027/1618-3169.55.4.283

Deffenbacher, K. A., Bornstein, B. H., Penrod, S. D., \& McGorty, E. K. (2004). A meta-analytic review of the effects of high stress on eyewitness memory. Law and Human Behavior, 28(6), 687-706. doi:10.1007/s10979-004-0565-x 
Hypotheses in human memory research

Dent, K. (2010). Dynamic visual noise affects visual short-term memory for surface color, but not spatial location. Experimental Psychology, 57(1), 17-26. doi: 10.1027/1618-3169/a000003

Flegal, K. E., Atkins, A. S., \& Reuter-Lorenz, P. A. (2010). False memories seconds later:The rapid and compelling onset of illusory recognition. Journal of Experimental Psychology: Learning, Memory, and Cognition, 36, 1331-1338. doi: 10.1037/a0019903

Galera, C., \& Lopes, E. J. (1995). Cronometria de processos mentais. Temas em Psicologia, 3, 1-10. Recuperado de http://pepsic. bvsalud. org/scielo.php?script=sci_arttext\&pid=\$1413-389X199500030000 2\&lng=pt\&tIng=pt

Galera, C., \& Lopes, E.J. (1997). Diagnostics of parallel and serial processing in a visual search task. Proceedings of the II Workshop on Cybernetic Vision (pp. 159-165). Los Alamitos, CA: IEEE Computer Society.

Gallo, D. (2010). False memories and fantastic beliefs: 15 years of the DRM illusion. Memory \& Cognition, 38, 833-848. doi: 10.3758/MC.38.7.833

Gardiner, J. M., Ramponi, C., \& Richardson-Klavehn, A. (1998). Experiences of remembering, knowing, and guessing. Consciousness and Cognition, 7, 1-26. doi: 10.1006/ccog.1997.0321

Green, D. M., \& Swets, J. A. (1966). Signal detection theory and psychophysics. New York: Wiley \& Sons, Inc.

Haarman, H., \& Usher, M. (2001). Maintenance of semantic information in capacity-limited item short-term memory. Psychonomic Bulltein \& Review, 8, 568-578. doi: 10.3758/BF03196193

Hamann, S. (2001). Cognitive and neural mechanisms of emotional memory. Trends in Cognitive Sciences, 5, 394-400. doi: 10.1016/ S1364-6613(00)01707-1

Jang, Y., Mickes, L., \& Wixted, J. T. (2012). Three tests and three corrections: Comment on Koen and Yonelinas (2010). Journal of Experimental Psychology: Learning, Memory, and Cognition, 38, 513-523. doi: 10.1037/a0025880

Jones, W. P., \& Anderson, J. R. (1982). Semantic categorization and high-speed scanning. Journal of Experimental Psychology: Learning, Memory \& Cognition, 8, 237-242. doi: 10.1037/0278-7393.8.3.237

Kemps, E., \& Andrade, J. (2012). Dynamic visual noise reduces confidence in short-term memory for visual information. Cognitive Processing, 13(2), 183-188. doi: 10.1007/s10339-011-0429-5

Kensinger, E. A. \& Schacter, D. L. (2006). Processing emotional pictures and words: effects of valence and arousal. Cognitive, Affective, \& Behavioral Neuroscience, 6(2), 110-126. doi:10.3758/CABN.6.2.110

Kensinger, E. A. (2004). Remembering emotional experiences: the contribution of valence and arousal. Reviews in the Neurosciences, 15(4), 241-252. doi: 10.1515/REVNEURO.2004.15.4.241

Kensinger, E. A., \& Corkin, S. (2004). Two routes to emotional memory: distinct neural processes for valence and arousal. Proceedings of the National Academy of Sciences of the U.S.A, 101(9), 3310-3315. doi: 10.1073/pnas.0306408101

Kosslyn, S. M. (1994). Image and brain: The resolution of the imagery debate. Cambridge: Mit Press.

LaBar, K. S., \& Cabeza, R. (2006). Cognitive neuroscience of emotional memory. Nature Reviews Neuroscience, 7, 54-64. doi:10.1038/nrn1825

Levine, L. J. (1997). Reconstructing memory for emotions. Journal of Experimental Psychology: General, 126(2), 165-177. doi: 10.1037/0096-3445.126.2.165

Logie, R. H. (1995). Visuo-spatial working memory. Hove: Lawrence Erlbaum Associates Ltd.
Logie, R. H. (2011). The functional organization and capacity limits of working memory. Current Directions in Psychological Science, 20(4), 240-245. doi: 10.1177/0963721411415340

Lopes, E. J., \& Garcia, R. B. (2014). On the possibility of using reaction time to study false memories. Psychology \& Neuroscience, 7(3), 393-397. doi: 10.3922/j.psns.2014.047

Luce, R. D. (1986). Response times: Their role in inferring elementary mental organization. New York: Oxford University Press.

Macmillan, N. A., \& Creelman, C. D. (2004). Detection theory: A user's guide (2nd ed.). New York: Cambridge University Press.

Mandler, G. (1980). Recognizing: the judgment of previous occurrence. Psychological Review, 87, 252-271. doi: 10.1037/0033-295X.87.3.252

Martin, N., \& Saffran, E. (1992). A computational account of deep dysphasia: Evidence from a single case study. Brain and Language, 32, 240-274. doi: 10.1016/0093-934X(92)90130-7

Martin, R. C., \& Romani, C. (1994). Verbal working memory and sentence comprehension: A multiple components view. Neuropsychology, 8 , 506-523. doi: 10.1037/0894-4105.8.4.506

Mazzoni, G.; \& Scoboria, A. (2007). False memories. In: F. T. Durso, R. S. Nickerson, S. T. Dumais, S. Lewandowsky, \& T. J. Perfect (Eds.), Handbook of applied cognition (2nd ed., pp. 787-813). Chichester, UK: John Wiley \& Sons Ltd.

McConnell, J., \& Quinn, J. G. (2000). Interference in visual working memory. The Quarterly Journal of Experimental Psychology: Section A, 53, 53-67. doi: 10.1080/713755873

McConnell, J., \& Quinn, J. G. (2003). Cognitive mechanisms of visual memories and visual images. Imagination, Cognition and Personality, 23(2-3), 201-207. doi: 10.2190/NX2P-NG6L-XY15-P78H

McConnell, J., \& Quinn, J. G. (2004). Complexity factors in visuo-spatial working memory. Memory, 12(3), 338-350. doi: 10.1080/09658210344000035

McGuire, W. J. (1997). Creative hypothesis generating in psychology: Some useful heuristics. Annual Review of Psychology, 48, 1-30. doi: 10.1146/annurev.psych.48.1.1

Mickes, L., Wixted, J. L., \& Wais, P.E. (2007). A direct test of the unequalvariance signal detection model of recognition memory. Psychonomic Bulletin \& Review, 14(5), 858-865. doi: 10.3758/BF03194112

Morrell, H. E. R., Gaitan, S., \& Wixted, J. T. (2002). On the nature of the decision axis in signal-detection-based models of recognition memory. Journal of Experimental Psychology: Learning, Memory, and Cognition, 28(6), 1095-1110. doi: 10.1037/0278-7393.28.6.1095

Orme, E. (2009). Identifying the functional architecture underlying multiple representations in visual working memory (Doctoral dissertation). Northumbria University. Retrieved from http://nrl.northumbria.ac.uk/2630/

Pearson, D. G. (2001). Imagery and the visuo-spatial sketchpad. In J. Andrade (Ed.), Working memory in perspective (pp. 33-59). Hove: Psychology Press.

Pereira, M. S., \& Galera, C. (n.d.). A integração da informação visual e espacial na memória de trabalho: evidências baseadas no efeito do ruído visual dinâmico (Master's thesis). Faculdade de filosofia, ciências e letras de Ribeirão Preto. Ribeirão Preto, SP. Retrieved from http://www.teses.usp.br/teses/disponiveis/59/59134/tde-29112012141651/pt-br.php

Pesta, B. J., Murphy, M. D., \& Sanders, R. E. (2001). Are emotionally charged lures immune to false memory? Journal of Experimental Psychology: Learning, Memory, and Cognition, 27(2), 328-338. doi: 10.1037/0278-7393.27.2.328 
Pezdek, K., \& Lam, S. (2007). What research paradigms have cognitive psychologists used to study "false memory", and what are the implications of these choices? Consciousness and Cognition, 16, 2-17. doi: 10.1016/j.concog.2005.06.006

Phelps, E. A., \& Sharot, T. (2008). How (and why) emotion enhances the subjective sense of recollection. Current Directions in Psychological Science, 17(2), 147-152. doi: 10.1111\%2Fj.1467-8721.2008.00565.x

Pickel, K. L. (2009). The weapon focus effect on memory for female versus male perpetrators. Memory, 17(6), 664-678. doi: $10.1080 / 09658210903029412$

Quinn, J. G. (2008). Movement and visual coding: The structure of visuo-spatial working memory. Cognitive Processing, 9, 35-43. doi: $10.1007 / \mathrm{s} 10339-007-0184-9$

Quinn, J. G. (2012). Theories and debate in visuo-spatial working memory: The questions of access and rehearsal. In V. Gyselinck \& F. Pazzaglia (Eds.), From mental imagery to spatial cognition and language: Essays in honour of Michel Denis (pp. 106-124). Hove: Psychology Press.

Quinn, J. G., \& McConnell, J. (1996). Indications of the functional distinction between the components of visual working memory. Psychologische Beitrage, 38(3-4), 355-367.

Quinn, J. G., \& McConnell, J. (2006). The interval for interference in conscious visual imagery. Memory, 14(2), 241-252. doi: $10.1080 / 09658210500210019$

Reisberg, D., \& Heuer, F. (2004). Remembering emotional events. In D. Reisberg \& P. Hertel (Eds.), Memory and emotion (pp. 3-41). New York: Oxford University Press.

Roediger, H. L., III; \& McDermott, K. B. (1995). Creating false memories: Remembering words not presented in lists. Journal of Experimental Psychology: Learning, Memory and Cognition, 21, 803-814. doi: 10.1037/0278-7393.21.4.803

Rugg, M. D., \& Yonelinas, A. P. (2003). Human recognition memory: A cognitive neuroscience perspective. Trends in Cognitive Sciences, 7, 313-319. doi: 10.1016/S1364-6613(03)00131-1

Salamé, P., \& Baddeley, A. D. (1982). Disruption of short-term memory by unattended speech: Implications for the structure of working memory. Journal of Verbal Learning and Verbal Behavior, 21(2), 150-164. doi: 10.1016/S0022-5371(82)90521-7

Santana, J. J. R. A. de, Godoy, J. P. M. C., Farias, K. L., Ferreira, H. C.P., \& Galera, C. (2013). Interference of dynamic visual noise on encoding visual information in working memory. Psicologia: Reflexão e Crítica, 26(4), 735-742. doi: 10.1590/S0102-79722013000400014

Schacter, D. L., Gallo, D. A., \& Kensinger, E. A. (2007). The cognitive neuroscience of implicit and false memories: Perspectives on processing specificity. The foundations of remembering: Essays in honor of Henry L. Roediger III, 353-378.

Schmolck, H., Buffalo, E. A., \& Squire, L. R. (2000). Memory distortions develop over time: recollections of O.J. Simpson trial veredict after 15 and 32 months. Psychological Science, 11(1), 39-45. doi: 10.1111/1467-9280.00212

Selmeczy, D., \& Dobbins, I. G. (2014). Relating the content and confidence of recognition judgments. Journal of Experimental Psychology: Learning, Memory, \& Cognition, 40, 66-85. doi: 10.1037/a0034059

Sene, A.S., Lopes, E. J., \& Rossini, J.C. (2014). Falsas memórias e tempo de reação: estudo com o procedimento de palavras associadas. Psychologica, 57, 25-40. doi: 10.14195/1647-8606_57_1_2
Shulman, H. G. (1972). Semantic confusion errors in short-term memory. Journal of Verbal Learning and Verbal Behavior, 11, 221-227. doi: 10.1016/S0022-5371(72)80080-X

Snodgrass, J. G., \& Corwin, J. (1988). Pragmatics of measuring recognition memory: Applications to dementia and amnesia. Journal of Experimental Psychology: General, 117, 34-50. doi: 10.1037/0096-3445.117.1.34

Stein, L. M., \& Cols. (2010). Falsas memórias: Fundamentos científicos e suas aplicações clínicas e jurídicas. Porto Alegre: Artmed.

Stein, L. M.; Feix, L. F.; \& Rohenkohl, G. (2006). Avanços metodológicos no estudo das falsas memórias: construção e normatização do procedimento de palavras associadas. Psicologia: Reflexão e Crítica, 19(2), 166-176. doi:10.1590/S0102-79722006000200002

Stein, L. M; \& Perguer, G. K. (2001). Criando falsas memórias em adultos por meio de palavras associadas. Psicologia: Reflexão e Crítica, 14(2), 353-366. doi: 10.1590/S0102-79722001000200010

Sternberg, S. (1966). High speed scanning in human memory. Science, 153, 652-654. doi: 10.1126/science.153.3736.652

Talarico, J. M., \& Rubin, D. C. (2003). Confidence, not consistency, characterizes flashbulb memories. Psychological Science, 14(5), 455-461. doi: 10.1111/1467-9280.02453

Townsend, J. T. (1990). Serial vs. parallel processing: Sometimes they look like Tweedledum and Tweedlee but they can (and should) be distinguished. Psychological Science, 1, 46-54. doi: 10.1111/j.14679280.1990.tb00067.x

Tulving. E. (1985). Memory and consciousness. Canadian Psychology, 26, 1-12. doi: 10.1037/h0080017

Turner, B. M., Van Zandt, T., \& Brown, S. (2011). A dynamic stimulusdriven model of signal detection. Psychological Review, 118, 583-613.

Van de Ven, V., Jacobs, C., \& Sack, A.T.(2012). Topographic contribution of early visual cortex to short-term memory consolidation: A transcranial magnetic stimulation study. The Journal of Neuroscience, 32(1), 4-11. doi: 10.1523/JNEUROSCI.3261-11.2012

Verde, M. F., \& Rotello, C. M. (2007). Memory strength and the decision process in recognition memory. Memory \& Cognition, 35(2), 254-262. doi: 10.3758/BF03193446

Vogel, E. K., Woodman, G. F., \& Luck, S. J. (2006). The time course of consolidation in visual working memory. Journal of Experimental Psychology: Human Perception and Performance, 32(6), 1436-1451. doi: 10.1037/0096-1523.32.6.1436

Welford, A. T. (1980). Reaction times. New York: Academic Press.

White, M. J. (1983). Prominent publications in cognitive psychology. Memory \& Cognition, 11(4), 423-427. doi: 10.3758/BF03202459

Wixted, J. T. (2007). Dual-process theory and signal-detection theory of recognition memory. Psychological Review, 114, 152-176. doi:10.1037/0033-295X.114.1.152

Yonelinas, A. P. (1994). Receiver-operating characteristics in recognition memory: Evidence for a dual-process model. Journal of Experimental Psychology: Learning, Memory, and Cognition, 20, 1341-1354. doi:10.1037/0278-7393.20.6.1341

Yonelinas, A. P. (2002). The nature of recollection and familiarity: A review of 30 years of research. Journal of Memory and Language, 46(3), 441-517. doi: 10.1006/jmla.2002.2864

Yonelinas, A.P., \& Parks, C. M. (2007). Receiver operating characteristics (ROCs) in recognition memory: A review. Psychological Bulletin, 133(5), 800-832. doi: 10.1037/0033-2909.133.5.800 
Antônio Jaeger, Doutor em Psicologia pela Universidade Federal do Rio Grande do Sul (UFRGS), Pós-doutorado em Psicologia na Universidade de Washington em St Louis (WASH-U/EUA), Pósdoutorado em Biociências na Universidade de São Paulo (USP) e Pós-doutorado em Psicologia na Pontifícia Universidade Católica do Rio Grande do Sul (PUCRS), é Professor Adjunto na Universidade Federal de Minas Gerais (UFMG). Endereço para correspondência:

Av. Antônio Carlos, 6627, UFMG, Departamento de Psicologia. Fone: (31) 3409-6279. E-mail: antonio.jaeger@gmail.com

Cesar Alexis Galera, Doutor em Psicologia Experimental pelo Instituto de Psicologia da Universidade de São Paulo, Pós-Doutorado na Concordia University (Montreal, Québec, Canadá), é Professor Titular da Faculdade de Filosofia, Ciências e Letras de Ribeirão Preto, Universidade de São Paulo (FFCLRP-USP). E-mail: algalera@usp.br

Lilian Milnitsky Stein, Doutora em Psicologia Cognitiva pela University of Arizona (EUA) e Pós-doutorado em Psicologia na Universidad de Barcelona (UB/Espanha), é Professora Titular do Programa de Pósgraduação em Psicologia da Pontifícia Universidade Católica do Rio Grande do Sul (PUCRS). E-mail: lilian@pucrs.br

Ederaldo José Lopes, Doutor em Psicobiologia pela Universidade de São Paulo (USP/, Ribeirão Preto, SP), Pós-Doutorado em Filosofia da Mente e Ciências Cognitivas na Universidade Federal de São Carlos (UFSCAR/São Carlos, SP), é Professor Titular do Instituto de Psicologia, Universidade Federal de Uberlândia (UFU).E-mail: ederaldo@ufu.br

Recebido em 14.Mai.15

Revisado em 07.Abr.16

Aceito em 30.Jun.16 